\title{
0034. Changes of TLR2, TLR4, MYD88 MRNA expressions on peripheral blood mononuclear cell in severe sepsis patients during treatment with thymosin $\alpha 1$
}

\author{
Z Tang ${ }^{*}$, J Wu, J Chen, B Ouyang, M Chen, X Guan \\ From ESICM LIVES 2014 \\ Barcelona, Spain. 27 September - 1 October 2014
}

\section{Introduction}

Severe sepsis is associated with a high mortality rate despite implementation of guidelinerecommendations. Thymosin alpha 1 (Ta1) has been used to treat severe sepsis as a promising beneficial immunomodulatory drug, but its mechanism remains unclear.

\section{Objectives}

To examine the TLR2, TLR4 and MyD88 mRNA expressions on human peripheral blood mononuclear cells during treatment.

\section{Methods}

A prospective randomized control trial was designed. Fifty-four patients with severe sepsis were enrolled and randomized into thymosin group (26 cases, treated with thymosin alpha 1) and control group (28 cases). TLR2, TLR4 and MyD88 mRNA were tested by RT-PCR on the day of enrollment, day 3 and day 7 after treatment in both groups, 28 day mortality in these patients was analyzed.

\section{Results}

There was no statistical significance between 28 day mortality rate in the control group and that of thymosin $\operatorname{group}(35.7 \%$ vs $23.1 \%, \mathrm{P}=0.310)$. TLR2, TLR4 and MyD88 mRNA expressions in the thymosin group were respectively increased on enrollment day, day 3 and day 7 , however, this increasing trend was not found in the control group. On day 3, TLR2 and TLR4 mRNA expressions in the thymosin group were higher than those in the control group $(2.31 \pm 0.79$ vs $1.83 \pm 0.51,7.31 \pm 0.79$ vs $6.55 \pm 0.92, \mathrm{P}<0.05)$. On day 7 , TLR2, TLR4 and MyD88 mRNA expressions in the thymosin group were higher than those in the control group $(2.75 \pm 1.17$ vs $1.63 \pm 0.36 ; 7.75 \pm 1.03$ vs $6.39 \pm 0.72 ; 4.26 \pm 0.77$ vs $3.77 \pm 0.68, \mathrm{P}<0.05)$.

\section{Conclusions}

Thymosin alpha 1 may increase TLR2,TLR4 and MyD88 mRNA expressions in severe sepsis patients.

\section{Published: 26 September 2014}

\section{References}

1. Hotchkiss RS, Karl IE: The pathophysiology and treatment of sepsis[J]. N Engl J Med 2003, 348(2):138-150.

2. Garaci E: Thymosin alpha1: a historical overview[J]. Ann N Y Acad Sci 2007, 1112:14-20.

3. Romani L, Bistoni F, Gaziano R, et al: Thymosin alpha 1 activates dendritic cells for antifungal Th1 resistance through toll-like receptor signaling[J]. Blood 2004, 103(11):4232-4239.

4. Peck-Palmer OM, Unsinger J, Chang KC, et al: Deletion of MyD88 markedly attenuates sepsis-induced $\mathrm{T}$ and $\mathrm{B}$ lymphocyte apoptosis but worsens survival[J]. J Leukoc Biol 2008, 83(4):1009-1018.

5. De Luca A, Montagnoli C, Zelante T, et al: Functional yet balanced reactivity to Candida albicans requires TRIF, MyD88, and IDO-dependent inhibition of Rorc[J]. J Immunol 2007, 179(9):5999-6008.

doi:10.1186/2197-425X-2-S1-O7

Cite this article as: Tang et al:: 0034. Changes of TLR2, TLR4, MYD88 MRNA expressions on peripheral blood mononuclear cell in severe sepsis patients during treatment with thymosin $\alpha 1$. Intensive Care Medicine Experimental 2014 2(Suppl 1):07. 